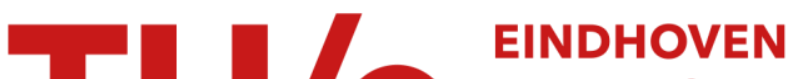 \\ UNIVERSITY OF \\ TECHNOLOGY
}

\section{A $1 \mathrm{MHz}$ wide bandgap power amplifier for high-precision applications}

\section{Citation for published version (APA):}

Yu, Q., Baeten, R. A. S., Lemmen, E., Vermulst, B., \& Wijnands, K. (2019). A $1 \mathrm{MHz}$ wide bandgap power amplifier for high-precision applications. In 2019 21st European Conference on Power Electronics and Applications (EPE'19 ECCE Europe) [8915497] Institute of Electrical and Electronics Engineers. https://doi.org/10.23919/EPE.2019.8915497

DOI:

10.23919/EPE.2019.8915497

Document status and date:

Published: 01/09/2019

\section{Document Version:}

Accepted manuscript including changes made at the peer-review stage

\section{Please check the document version of this publication:}

- A submitted manuscript is the version of the article upon submission and before peer-review. There can be important differences between the submitted version and the official published version of record. People interested in the research are advised to contact the author for the final version of the publication, or visit the $\mathrm{DOI}$ to the publisher's website.

- The final author version and the galley proof are versions of the publication after peer review.

- The final published version features the final layout of the paper including the volume, issue and page numbers.

Link to publication

\section{General rights}

Copyright and moral rights for the publications made accessible in the public portal are retained by the authors and/or other copyright owners and it is a condition of accessing publications that users recognise and abide by the legal requirements associated with these rights.

- Users may download and print one copy of any publication from the public portal for the purpose of private study or research.

- You may not further distribute the material or use it for any profit-making activity or commercial gain

- You may freely distribute the URL identifying the publication in the public portal.

If the publication is distributed under the terms of Article 25fa of the Dutch Copyright Act, indicated by the "Taverne" license above, please follow below link for the End User Agreement:

www.tue.nl/taverne

Take down policy

If you believe that this document breaches copyright please contact us at:

openaccess@tue.nl

providing details and we will investigate your claim. 


\title{
A 1 MHz Wide Bandgap Power Amplifier for High-Precision Applications
}

\author{
Qihao Yu, Rik Baeten, Erik Lemmen, Bas Vermulst, Korneel Wijnands \\ Department of Electrical Engineering, Eindhoven University of Technology \\ P.O. Box 513, 5600MB \\ Eindhoven, The Netherlands \\ Email: q.yu@tue.nl \\ URL: http://www.tue.nl/epe
}

\section{Acknowledgments}

This research was supported by Prodrive Technologies B.V.. Assistance provided by Jory Verberne was greatly appreciated.

\section{Keywords}

$\ll$ Harmonics $\gg, \ll$ Wide bandgap devices $\gg, \ll$ High frequency power converter $\gg, \ll$ Industrial application $\gg$.

\begin{abstract}
The goal of this research is to optimize the total inductor volume of the extra bias inductor opposed current converter. Wide bandgap semiconductors are used to raise the switching frequency to $1 \mathrm{MHz}$ for a further decrease of the inductor volume. The research is validated with a high-precision current amplifier prototype.
\end{abstract}

\section{Introduction}

Switched-mode power converters (SMPCs) are widely used in industry. For some applications, such as lithography and magnetic resonance imaging (MRI), their precision and linearity are important. Taking lithography for example, the position error of the moving stage is determined by the non-linearity error of the current amplifier [1]. In order to obtain a nm position accuracy, lithography requires less than $-100 \mathrm{~dB}$ current distortion for the high-precision motor control. With the development of industry, those applications are raising their demands for higher bandwidth and smaller volume [2].

Increasing the switching frequency of the power converter is a solution to meet those demands since it increases bandwidth and reduces the volume of the filter components. However, higher switching frequencies cause larger power dissipation and temperature rise on the switches, which is a challenge for the widely-used Si-based MOSFETs. Besides, due to the finite turn-on and turn-off time of the switches, a dead-time is required in half-bridge (HB) or full-bridge (FB) converter. When the switching frequency becomes higher, the dead-time results in larger distortion, which is the most significant source of distortion in this topology [3].

Wide bandgap semiconductors, such as Gallium Nitride $(\mathrm{GaN})$ transistors are an alternative to the Sibased MOSFETs. Since the switching speed of GaN transistors is faster than Si-based MOSFETs, the switching loss is largely reduced thus making it possible to switch at a higher frequency. To overcome the dead-time distortion, a different topology named by opposed current converter (OCC) is proposed in [4], which fully eliminates the dead-time and results in high linearity.

In [5] and [6], it is proved that the OCC topology has good linearity and is an appropriate substitute of $\mathrm{HB}$ or FB converter. A comparison of different topologies combined with the $\mathrm{GaN}$ transistors is done 
based on simulations in [7]. It shows that GaN transistors are promising to use in OCC topology but it's not verified by experimental results yet. One of the disadvantages of the OCC topology is that the total inductor volume is increased due to the extra bias current to maintain the continuous current mode [8]. In [9], an extra bias inductor opposed current converter (ELOCC) is proposed to reduce the total inductor volume but the volume is not optimized yet.

In this research, the total inductor volume of ELOCC topology is modeled based on [9] but the accuracy of the model is improved by taking the rms value of the variable inductor ripple current into consideration. The total inductor volume is optimized by adapting the inductor current ripple ratio. GaN transistors are used to raise the switching frequency to $1 \mathrm{MHz}$ for a further decrease of the inductor volume. The bandwidth of the converter is also improved. The research is verified by a high-precision current amplifier prototype with $320 \mathrm{~V}$ output voltage and $12.5 \mathrm{~A}$ output current.

\section{The Extra Bias Inductor Opposed Current Converter}

Compared to the equivalent $\mathrm{HB}$ converter, the OCC has two additional blocking diodes and one additional inductor, which makes it possible for the two switches to conduct at the same time. Consequently, no dead-time is required thus the dead-time distortion is eliminated. The two blocking diodes also force the filter inductor current going through each leg in one direction. If a bias current $i_{\text {bias }}$ is added to each leg, the current in the filter inductor becomes continuous thus eliminating the distortion caused by the discontinuous current mode (DCM). Due to the doubled number of the filter inductors and the extra bias current through the filter inductors, the total filter inductor volume of OCC becomes much larger compared to the equivalent $\mathrm{HB}$ converter [8].

A volume reduction method by adding an extra bias filter inductor $L_{b}$, which is referred to the ELOCC, is shown in Fig. 1 . The dc bias current mainly goes through the bias inductor $L_{b}$, which decreases the peak current and rms current of the filter inductors thus reducing the total inductor volume. The waveform of the bias inductor, filter inductor and output current of ELOCC is shown in Fig. 2.

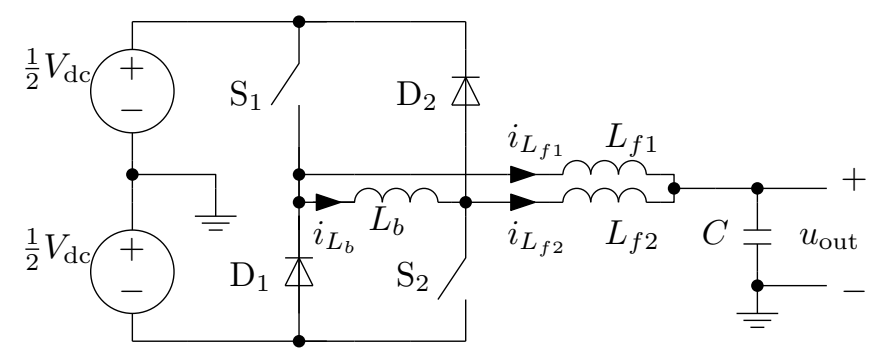

Fig. 1: The extra bias inductor opposed current converter (ELOCC) with output filter.

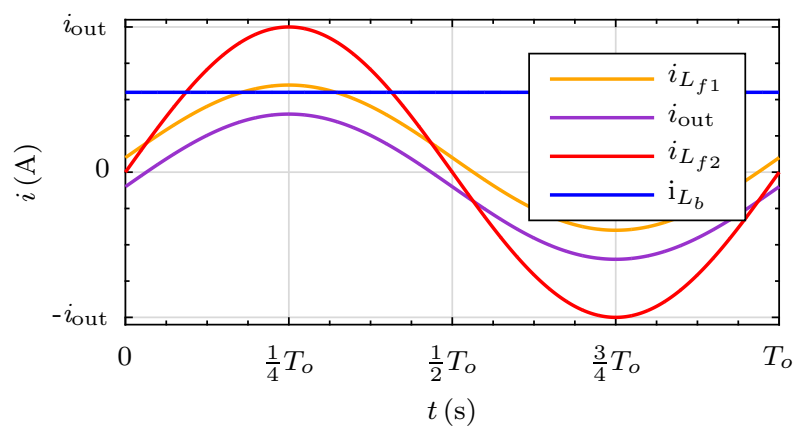

Fig. 2: The waveform of filter inductor and output current of OCC topology.

The area-product method is used to estimate the volume of the inductor as described in [10] and defined 
by

$$
A_{P}=\frac{L}{\hat{B} J K_{u}} \hat{i} I
$$

where $L$ is the inductance, $\hat{B}$ is the peak magnetic flux density, $J$ is the rms current density, $K_{u}$ is the window utilization, $\hat{i}$ is the peak current and $I$ is the rms current. To make volume comparison for the same core material, $\hat{B}, J$ and $K_{u}$ are assumed to be equal for all inductors. The volume of the inductor is estimated by

$$
V_{L}=K_{\mathrm{vol}} A_{P}^{0.75},
$$

where $K_{\mathrm{vol}}$ is the core's geometrical constant and can be regarded as a constant for the inductors discussed in this section. The filter current ripple $\Delta i_{L f}$ during each switching cycle is given by

$$
\Delta i_{L f}=\frac{V_{\mathrm{dc}}}{L_{f}} \frac{1}{8} T_{\mathrm{sw}}\left(1-m^{2}\right)=k_{\mathrm{r}} \hat{i}_{\mathrm{out}}\left(1-m^{2}\right),
$$

where $T_{\mathrm{sw}}$ is the switching period, $m$ is the modulation index, $\hat{i}_{\text {out }}$ is the maximum output current and $k_{\mathrm{r}}$ is the filter current ripple ratio. For a sinusoidal output, the ripple current is variable in each switching cycle therefore the rms value of the ripple current is also variable. The rms ripple current during a full output period is governed by

$$
I_{\text {rms,ripple }}=\hat{i}_{\text {out }} \sqrt{\frac{1}{3} k_{\mathrm{r}}^{2}\left(\frac{3}{8} M_{m}^{4}-M_{m}^{2}+1\right)}
$$

where $M_{m}$ is the modulation depth and assumed as 0.9 in this research. The calculated rms ripple current is about $66 \%$ of the estimation in [9] with a fixed ripple current assumption. Therefore, a smaller filter inductor volume is expected. The area-product of the each filter inductor is calculated as

$$
A_{P, L_{f}}=\frac{V_{\mathrm{dc}} T_{\mathrm{sw}} \hat{i}_{\mathrm{out}}}{8 \hat{B} J K_{u} k_{\mathrm{r}}}\left[\frac{1}{2}+k_{r}+Q_{L f}\left(\frac{1}{2}+k_{0}\right)\right] \sqrt{\frac{1}{8}+Q_{L f}^{2}\left(\frac{1}{2}+k_{0}\right)^{2}+\frac{1}{3} k_{r}^{2}\left(\frac{3}{8} M_{m}^{4}-M_{m}^{2}+1\right)},
$$

where $k_{0}$ is the offset current coefficient factor and $Q_{L f}$ is one of the current distribution coefficients and defined by

$$
Q_{L f}=\max \left(\frac{R_{L b}}{R_{L b}+2 R_{L f}}, \frac{L_{b}}{L_{b}+2 L_{f}}\right),
$$

where $R_{L b}$ and $R_{L f}$ are the parasitic series resistance of the bias inductor and filter inductor respectively. The area-product of the bias inductor is given by

$$
\begin{aligned}
A_{P, L_{b}}= & \frac{V_{\mathrm{dc}} T_{\mathrm{sw}} k_{L b}}{8 \hat{B} J K_{u}} \hat{i}_{\mathrm{out}}\left[Q_{L b}\left(\frac{1}{2}+k_{0}\right)+\frac{m_{\mathrm{bias}} k_{r}}{k_{L b}}\left(1+\hat{m}_{\mathrm{out}}^{\prime}\right)\right] \\
& \times \sqrt{Q_{L b}^{2}\left(\frac{1}{2}+k_{0}\right)^{2}+\frac{1}{3}\left[1+\frac{1}{2} \hat{m}_{\text {out }}^{\prime 2}\left(1+m_{\text {bias }}\right)\right]\left(\frac{m_{\mathrm{bias}} k_{r}}{k_{L b}}\right)^{2}},
\end{aligned}
$$

where $k_{L b}$ is the value of $L_{b}$ relative to $L_{f}, m_{\text {bias }}$ is the bias voltage modulation index, $\hat{m}_{\text {out }}^{\prime}$ is the maximum value of the relative modulation index and is equivalent to

$$
\hat{m}_{\text {out }}^{\prime}=\frac{M_{m}}{1-\frac{1}{2} m_{\text {bias }}}
$$


and $Q_{L b}$ is the other current distribution coefficient expressed as

$$
Q_{L b}=\max \left(\frac{2 R_{L f}}{R_{L b}+2 R_{L f}}, \frac{2 L_{f}}{L_{b}+2 L_{f}}\right) .
$$

The total inductor volume is estimated as

$$
V_{L, \mathrm{EL}}=K_{\mathrm{vol}}\left(2 A_{P L_{f, \mathrm{EL}}}^{0.75}+A_{P L_{b}}^{0.75}\right) .
$$

For an equivalent $\mathrm{HB}$, the area-product is governed by

$$
A_{P, L_{\mathrm{HB}}}=\frac{V_{\mathrm{dc}} T_{\mathrm{sw}}}{16 \hat{B} J K_{u}} \hat{i}_{\mathrm{out}} \frac{1+2 k_{r}}{k_{r}} \sqrt{\frac{1}{2}+\frac{4}{3} k_{r}^{2} M_{m}} .
$$

The volume of the filter inductor in a HB is estimated as

$$
V_{L, \mathrm{HB}}=K_{\mathrm{vol}} A_{P, L_{\mathrm{HB}}}^{0.75} .
$$

The total inductor volume is highly dependent on the current distribution coefficients $Q_{L b}$ and $Q_{L f}$. For different $k_{\mathrm{r}}$ and $k_{\mathrm{o}}$, there are different optimized value of $Q_{L b}$ and $Q_{L f}$. To make a fair comparison to [9], the relative total inductor volume compared to the equivalent HB is calculated and the result is shown in Fig. 3. $V_{L, \mathrm{HB}}$ is the inductor volume of $\mathrm{HB}$ with $k_{\mathrm{r}}=0.2$ and used as a reference voltage for comparison. The minimum total inductor volume is achieved when $k_{L b}=0.0147$, which is about a factor of 1.32 of an equivalent $\mathrm{HB}$ and is about $8 \%$ smaller than the expected value in [9]. A theoretical volume reduction of up to $66 \%$ can be achieved by using the ELOCC topology.

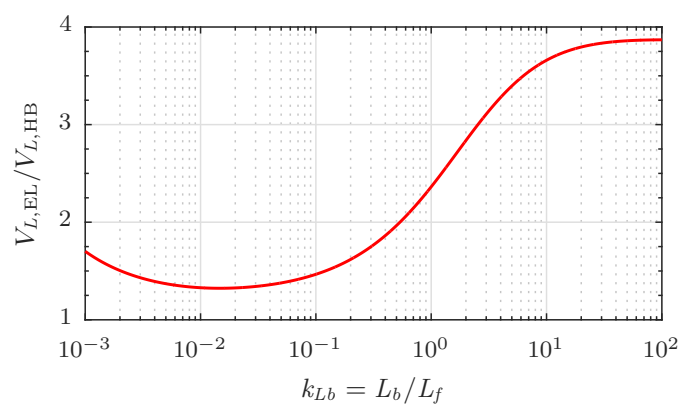

Fig. 3: The relative inductor volume of ELOCC to $\mathrm{HB} V_{L, \mathrm{EL}} / V_{L, \mathrm{HB}}$ as a relation to $k_{L b}$.

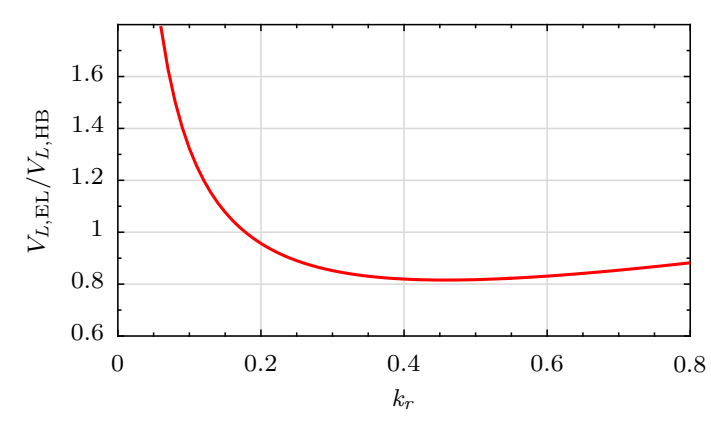

Fig. 4: The relative inductor volume of ELOCC as a function of $k_{\mathrm{r}}$.

The total inductor volume can be optimized by $k_{\mathrm{r}}$ with a fixed $k_{\mathrm{Lb}}$, which is depicted in Fig. 4 . There is an optimized $k_{\mathrm{r}}=0.45$, which result in a factor of 0.82 of $V_{L, \mathrm{HB}}$.

\section{Prototype Design}

A current amplifier prototype is built to verify the performance and functionality of the full-bridge equivalent ELOCC topology using wide bandgap semiconductors. The power-stage is depicted in Fig. 5. This current amplifier is designed for a high-precision motor drive application. The requirement of the prototype is depicted in Table I. The prototype power stage is built with GS66508T 650V enhancement mode $\mathrm{GaN}$ transistors and C3D10065E SiC Schottky diodes to achieve a switching frequency of $1 \mathrm{MHz}$.

Decoupled output and bias current controllers $C_{\text {out }}$ and $C_{\text {bias }}$ are used in the prototype. An overview of the control diagram is shown in Fig. 6. The output current is sampled at $500 \mathrm{kHz}$ sampling frequency and the bias current is sampled at $1 \mathrm{MHz}$ sampling frequency. All the controllers are updated at $2 \mathrm{MHz}$ frequency and aligned with the asymmetrically sampled triangular carrier wave PWM. 


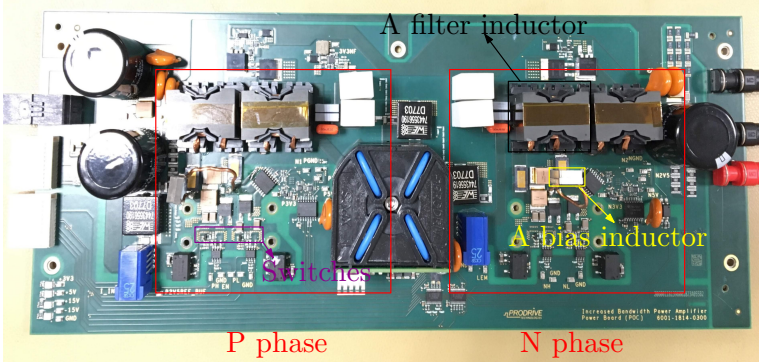

Fig. 5: The power-stage of the prototype.

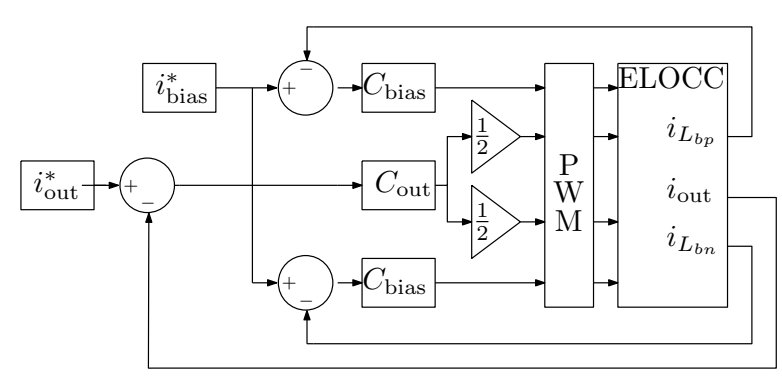

Fig. 6: ELOCC proposed control diagram.

Table I: The requirement of the current amplifier

\begin{tabular}{c|c|c|l||c|c|c|l}
\hline \hline Parameter & Value & Unit & Description & Parameter & Value & Unit & Description \\
\hline$V_{\mathrm{dc}}$ & 360 & $\mathrm{~V}$ & Dc voltage & $f_{\mathrm{sw}}$ & 1 & $\mathrm{MHz}$ & Switching frequency \\
$\hat{v}_{\text {out }}$ & 320 & $\mathrm{~V}$ & Output voltage & $\hat{i}_{\text {out }}$ & 12.5 & $\mathrm{~A}$ & Output current \\
$L_{\mathrm{x}}$ & 2.5 & $\mathrm{mH}$ & Load inductor & $R$ & 4 & $\Omega$ & Load resistor \\
\hline \hline
\end{tabular}

The inductor design is optimized according to the calculation in previous section. With the existing magnetic core, the filter inductor is selected as $36 \mu \mathrm{H}$ and the current ripple $k_{\mathrm{r}}$ is selected as 0.2 for the full-bridge equivalent ELOCC considering the core loss and saturation effect. The bias inductor is selected as $6.8 \mu \mathrm{H}$ considering the di/dt limitation. Therefore, $k_{\mathrm{Lb}}$ is 0.189 , which results in a total inductor volume a factor of 1.61 of an equivalent $\mathrm{HB}$ converter theoretically. The total inductor volume is shown in Fig. 5, which matches with the theoretical estimation.

\section{Simulation and Experimental Results}

Simulated current waveforms with closed-loop configuration is shown in Fig. 7. The simulation model is based on the selected components and conducted in Simulink/PLECS. The parasitics of all the components, the on-resistance variance and inductor saturation effect are neglected. The output current magnitude $\hat{i}_{\text {out }}$ is $12.5 \mathrm{~A}_{\mathrm{pk}}$ and the bias inductor current $i_{L_{b}}$ is set as $5 \mathrm{~A}_{\mathrm{dc}}$. The frequency spectrum of the output current is shown in Fig. 8.

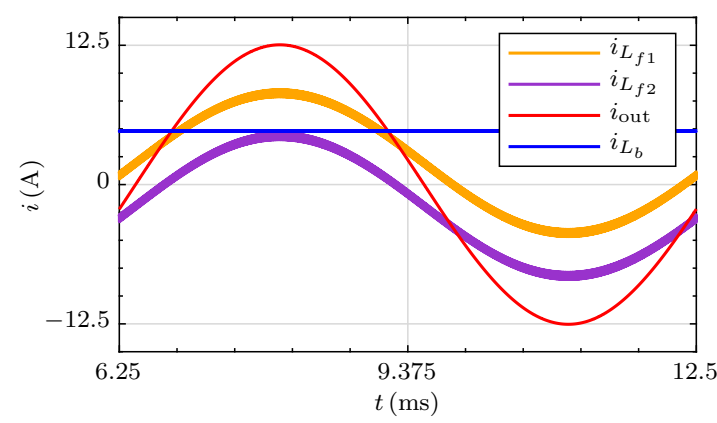

Fig. 7: The simulated waveforms of filter inductors, bias inductor, output current of OCC topology. A constant bias current $i_{\text {bias }}$ is added to the two legs.

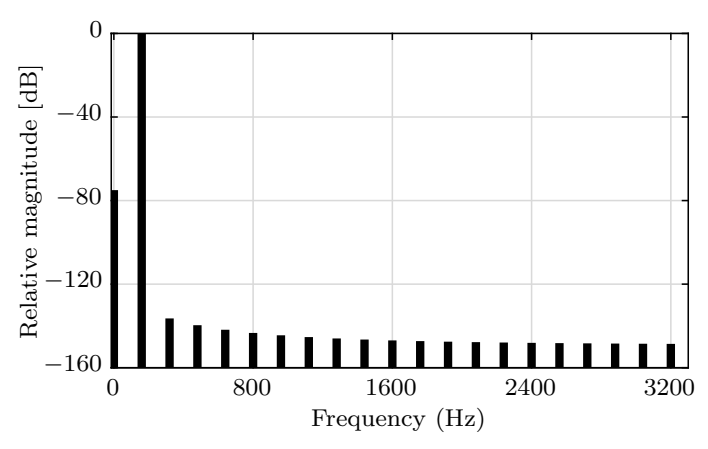

Fig. 8: The simulated frequency spectrum of the $12.5 \mathrm{~A}_{\mathrm{pk}} 160 \mathrm{~Hz}$ sinusoidal output current at $360 \mathrm{~V}$.

As can be seen, the bias current and the output current are fully decoupled in the closed-loop control. The waveform of filter inductor current $i_{L_{f 1}}$ and $i_{L_{f 2}}$ are both sinusoidal while $i_{L_{f 1}}$ is larger than $i_{L_{f 2}}$ because the switch node voltage $u_{\mathrm{sn} 1}$ is larger than $u_{\mathrm{sn} 2}$ in order to create a positive bias current. The expected relative magnitude ( $\mathrm{dB}$ relative to the first order harmonic) of all the harmonic distortion is below -135 $\mathrm{dB}$ and the higher order harmonics are always lower. 
Measurements are conducted to verify the design. The bias current of the $\mathrm{P}$ phase and the output current are measured with current probes which are connected to a Tektronix MSO54 oscilloscope. The measured waveforms are post-processed in MATLAB for better visualization. Waveforms of $12.5 \mathrm{~A}_{\mathrm{pk}}$ output current and $5 \mathrm{~A}_{\mathrm{dc}}$ bias current at $360 \mathrm{~V}$ dc supply voltage are shown in Fig. 9. Because of the relatively low sampling frequency compared to the frequency of the bias current, the bias current is not controlled well and coupled with the output current.

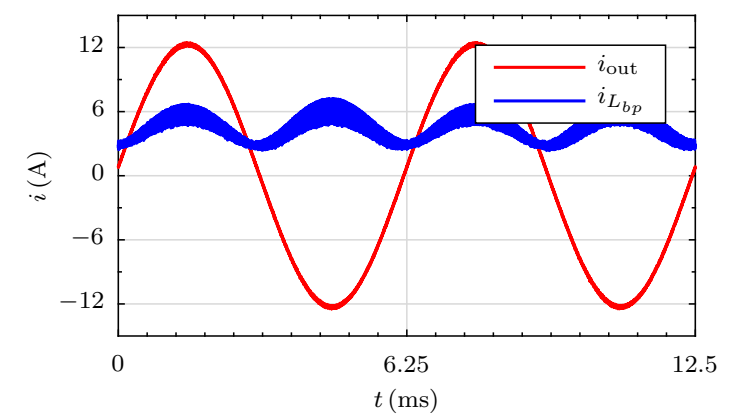

Fig. 9: Waveforms at $12.5 \mathrm{~A}_{\mathrm{pk}} 160 \mathrm{~Hz}$ output current and $360 \mathrm{~V}$ dc supply voltage.

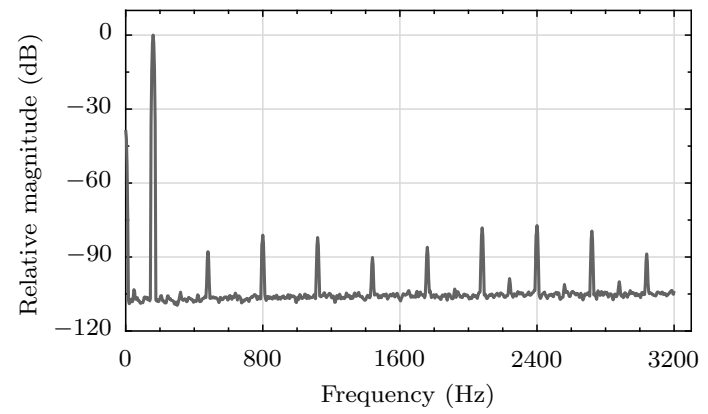

Fig. 10: The frequency spectrum of the $12.5 \mathrm{~A}_{\mathrm{pk}}$ $160 \mathrm{~Hz}$ sinusoidal output current at $360 \mathrm{~V}$.

The linearity of the current amplifier is tested by measuring the distortion harmonics in the output current under the same working condition. The output current is measured with a high linearity current sensor and analyzed in SR785 spectrum analyzer. A frequency spectrum of the output current is shown in Fig. 10.

The relative amplitude of the noise floor for this current amplifier is as low as $-115 \mathrm{~dB}$. The relative amplitude of the third order harmonic is $-88 \mathrm{~dB}$. The highest harmonic is the 15 th order harmonic, the relative amplitude of which is $-77 \mathrm{~dB}$. Other harmonics have lower amplitude. The measured distortion is higher than the simulation because of all the non-linear factors, including PWM distortion, transistor on-resistance variation and inductor saturation effect.

The distortion of the existing product, which is a similar amplifier based on the FB topology and working at $187.5 \mathrm{kHz}$ switching frequency, is $-53 \mathrm{~dB}$ under the same output condition. Compared to the product, the prototype based on the ELOCC topology improves the third order harmonic rejection by $35 \mathrm{~dB}$ and gives a much better linearity. The bandwidth of the prototype is larger than $20 \mathrm{kHz}$ tested with a 500 $\mu \mathrm{H}$ load inductor and $4.7 \Omega$ load resistor, which is already a significant improvement. The volume of the power stage is also decreased by more than $40 \%$ compared to the existing product.

\section{Conclusion}

In this paper, the total inductor volume of ELOCC topology is modeled with an improved accuracy and optimized by selecting the optimized current ripple ratio. GaN transistors are used to raise the switching frequency to $1 \mathrm{MHz}$ in order to reduce the total inductor volume further. As a result, the volume of the power stage is reduced by $40 \%$ compared to the previous product. The bandwidth and the linearity are also improved. It is shown that the GaN transistors are effective in reducing the switching loss and promising to use in high-precision converters.

Further research could be focused on a better decoupled control of the bias current and output current in order to get better rejection for higher order harmonics.

\section{References}

[1] S. Settels, J. van Duivenbode, and J. Duarte, "Impact of amplifier errors on position loop accuracy of high-precision moving stages," in 2017 19th European Conference on Power Electronics and Applications (EPE'17 ECCE Europe). IEEE, 2017, pp. P-1.

[2] H. Bulter, "Position control in lithographic equipment an enabler for current-day chip manufacturing," IEEE Control System Magazine, pp. 28-47, 2011. 
[3] D. C. Moore, M. Odavic, and S. M. Cox, "Dead-time effects on the voltage spectrum of a pwm inverter," IMA Journal of Applied Mathematics, vol. 79, no. 6, pp. 1061-1076, 2014.

[4] J. Schellekens, J. Duarte, H. Huisman, and M. Hendrix, "Elimination of zero-crossing distortion for highprecision amplifiers," in IECon 2011-37th Annual Conference on IEEE Industrial Electronics Society. IEEE, 2011, pp. 3370-3375.

[5] G. R. Stanley and K. M. Bradshaw, "Precision dc-to-ac power conversion by optimization of the output current waveform-the half bridge revisited," IEEE Transactions on Power Electronics, vol. 14, no. 2, pp. 372-380, 1999.

[6] Z. Yao, L. Xiao, and Y. Yan, “Dual-buck full-bridge inverter with hysteresis current control,” IEEE Transactions on Industrial Electronics, vol. 56, no. 8, pp. 3153-3160, 2009.

[7] M. Mauerer, A. Tüysüz, and J. W. Kolar, "Distortion analysis of low-thd/high-bandwidth gan/sic class-d amplifier power stages," in Energy Conversion Congress and Exposition (ECCE), 2015 IEEE. IEEE, 2015, pp. 2563-2571.

[8] J. Schellekens, "A class of robust switched-mode power amplifiers with highly linear transfer characteristics: on the elimination of zero-crossing distortion in switching converters," Ph.D. dissertation, Technische Universiteit Eindhoven, 2014.

[9] E. Lemmen, J. M. Schellekens, C. G. Wijnands, and J. L. Duarte, "Advances in high-precision amplifiers - the extra 1 opposed current converter," IEEE Transactions on Power Electronics, vol. 30, no. 10, pp. 5691-5700, 2015.

[10] C. W. T. McLyman, Transformer and inductor design handbook. CRC press, 2016. 